\title{
Amount Recovered Normalized by Weight
}

National Cancer Institute

\section{Source}

National Cancer Institute. Amount Recovered Normalized by Weight. NCI Thesaurus.

Code C92366.

The cumulative amount recovered from the specimen type, from dosing to end of the current collection interval divided by the weight. 